ORIGINAL ARTICLE

\title{
Risk Factors for Lymphedema in Breast Cancer Survivors Following Axillary Lymph Node Dissection
}

\author{
Yoshiteru Akezaki, RPT, PhD ${ }^{\text {a }}$ Ritsuko Tominaga, RPT ${ }^{\text {b }}$ Masato Kikuuchi, OTR ${ }^{\text {b }}$ \\ Hideaki Kurokawa, RPT ${ }^{b}$ Makiko Hamada, RPT ${ }^{b}$ Kenjiro Aogi, MD ${ }^{c}$ Shozo Ohsumi, MD, PhD ${ }^{c}$ \\ Tetsuya Tsuji, MD, PhD ${ }^{d}$ Susumu Kawamura, MD ${ }^{\mathrm{e}}$ and Shinsuke Sugihara MD, PhD ${ }^{\text {b, }}$
}

Objective: The aim of the current study was to assess the risk factors for developing lymphedema following breast cancer treatment. Methods: The subjects of this study were 238 consecutive patients who underwent axillary lymph node dissection for breast cancer at Shikoku Cancer Center. The study variables were the occurrence of lymphedema, the body mass index, the follow-up period, the drain removal time, the level of lymph node dissection, the presence or absence of co-resident household members, radiation therapy, neoadjuvant chemotherapy, and adjuvant chemotherapy. Results: We observed lymphedema in $23.9 \%$ of patients after axillary lymph node dissection for breast cancer. Neoadjuvant chemotherapy and adjuvant chemotherapy using docetaxel and cyclophosphamide increased the risk of developing lymphedema $(\mathrm{P}<0.05)$. Conclusions: Those patients treated with neoadjuvant chemotherapy and adjuvant chemotherapy using docetaxel and cyclophosphamide should be observed closely after axillary lymph node dissection, and appropriate intervention should be considered from an early stage.

Key Words: axillary lymph node dissection; breast cancer; chemotherapy; lymphedema; upper limb

\section{INTRODUCTION}

Lymphedema is one of the most burdensome complications of breast cancer treatment. ${ }^{1)}$ It is caused by functional overload of the lymphatic system in which the lymph volume exceeds the transport capabilities. ${ }^{2)}$ Lymphedema causes pain, functional disability, deformity, and recurrent infections within the edematous limb. ${ }^{3-7)}$ Women with lymphedema also experience depression, anxiety, social isolation, and sexual problems. ${ }^{7,8)}$ Therefore, identifying the risk factors for developing lymphedema is important to enable measures to be taken to reduce its occurrence. The survival rate for early breast cancer patients continues to improve. As a result, the adverse effects of post-treatment complications, such as lymphedema, on the long-term quality of life (QOL) have become increasingly serious problems.

Numerous studies have found that lymphedema is associated with radiation therapy, ${ }^{9,10)}$ obesity, ${ }^{11-15)}$ and chemotherapy. ${ }^{13,16)}$ However, in Japan, the factors associated with lymphedema development after breast cancer surgery are not well established. The aim of the current study was to assess the risk factors for developing lymphedema following breast cancer treatment.

\section{SUBJECTS AND METHODS}

\section{Subjects}

The subjects of this study were 238 consecutive patients (238 women) who underwent axillary lymph node dissection for breast cancer at Shikoku Cancer Center between Novem-

Received: July 2, 2019, Accepted: November 14, 2019, Published online: November 23, 2019

a Division of Physical Therapy, Kochi Professional University of Rehabilitation, Kochi, Japan

${ }^{b}$ Department of Rehabilitation Medicine, National Hospital Organization Shikoku Cancer Center, Ehime, Japan

${ }^{c}$ Department of Breast Surgery, National Hospital Organization Shikoku Cancer Center, Ehime, Japan

d Department of Rehabilitation Medicine, Keio University Hospital, Tokyo, Japan

e Department of Plastic and Reconstructive Surgery, National Hospital Organization Shikoku Cancer Center, Ehime, Japan

${ }^{\mathrm{f}}$ Department of Orthopaedic Oncology, National Hospital Organization Shikoku Cancer Center, Ehime, Japan

Correspondence: Yoshiteru Akezaki, Division of Physical Therapy, Kochi Professional University of Rehabilitation, Otu-1139-3, Takaoka-Machi, Tosa, Kochi 781-1102, Japan, E-mail: akezakiteru@yahoo.co.jp

Copyright (C) 2019 The Japanese Association of Rehabilitation Medicine 
ber 2013 and November 2016. The average age \pm standard deviation (SD) at the time of the study was $56.4 \pm 12.3$ years, and the mean follow-up period was $31.2 \pm 10.8$ months.

\section{Ethical Approval Statement}

Shikoku Cancer Center Ethics Committee approved this study, and written informed consent was obtained from each participant (Approval No. 2018-45).

\section{Outcome Measures}

All patients gave their informed consent to participate in this study. The variables studied were the occurrence of lymphedema, the body mass index (BMI), the follow-up period, the drain removal time, the level of lymph node dissection, the presence or absence of co-resident household members, radiation therapy, neoadjuvant chemotherapy, and adjuvant chemotherapy.

Lymphedema in outpatients was diagnosed by a doctor following visual inspection, palpation, and confirmation of circumference differences. Inspections evaluated the visibility of veins or tendons in the hand. Palpation evaluated the presence of compression marks, Stemmer's sign, and skin hardness. Circumference differences were evaluated by comparing the surgical upper extremity and the contralateral upper extremity after surgery, and by comparing the ipsilateral upper extremity before and after surgery. The definition of lymphedema used in this study was that patients with stage one, two, or three lymphedema as defined by the International Society of Lymphology were categorized as the lymphedema group; those categorized as stage zero made up the non-lymphedema group. Occupational therapists and physical therapists checked for lymphedema once a month for the first 3 months after surgery, and any potential sign of lymphedema was reported to the doctor for further investigation. From 3 months after surgery, patients were examined for lymphedema by a doctor when they visited the hospital for adjuvant therapy. If the patients themselves suspected that they were developing lymphedema, they visited the outpatient clinic for confirmation of lymphedema. BMI was measured before surgery.

Radiation therapy was classified into three categories: irradiation of the subclavian lymph node and the anterior chest, irradiation of the anterior chest only, and no radiation therapy. Neoadjuvant chemotherapy was classified as yes or no. The basic policy for neoadjuvant chemotherapy was for it to be administered in patients who had lymph node metastasis at the time of diagnosis or whose tumor diameter was large $(\geq 3 \mathrm{~cm})$.
Adjuvant chemotherapy was classified as docetaxel and cyclophosphamide (TC); TC + trastuzumab; doxorubicin and cyclophosphamide (AC) + paclitaxel; trastuzumab + paclitaxel; paclitaxel; and other. The basic method for determining the adjuvant chemotherapy regimen was as follows: node-negative patients were treated with TC, whereas node-positive patients were treated with AC or epirubicin + cyclophosphamide followed by taxane (docetaxel or paclitaxel). Furthermore, patients with hormone receptor-positive and only one to three lymph node metastases were treated with TC.

\section{Rehabilitation Program}

During hospitalization before surgery, upper limb exercise instruction was given. The patients were instructed not to mobilize the shoulder beyond $90^{\circ}$ of abduction and flexion until postoperative day four (or until the day of drain removal). Once the drains were removed, no restriction of movement was imposed except that resulting from pain. After discharge, patients were encouraged to perform exercises home and were provided with a DVD demonstrating upper limb exercises. At the time of discharge, occupational therapists and physical therapists instructed patients to visit the hospital if postoperative adverse events, including lymphedema, occurred.

\section{Statistical Analysis}

The differences between the lymphedema group and the non-lymphedema group were compared using the independent $t$-test, the $\chi^{2}$ test, and the Mann-Whitney $U$ test. Variables with $\mathrm{P}<0.20$ by these tests were selected for multivariate analysis. Logistic regression was utilized to assess the relationship between risk factors and lymphedema. The variables with $\mathrm{P}<0.05$ were retained in the final multivariate analysis. SPSS software version 22.0 (IBM, Tokyo, Japan) was used to analyze the collected data.

\section{RESULTS}

We observed lymphedema in $23.9 \%$ (57/238) of patients after axillary lymph node dissection for breast cancer. The time of diagnose of lymphedema was on average $10.5 \pm 8.3$ months after surgery.

The results of the univariate analysis are shown in Table $\mathbf{1 .}$ The drain removal time, the level of lymph node dissection, neoadjuvant chemotherapy, adjuvant chemotherapy using $\mathrm{TC}$, and adjuvant chemotherapy using AC + paclitaxel were significantly different between the lymphedema group and 
Table 1. Comparison of variables between the lymphedema and the non-lymphedema groups

\begin{tabular}{|c|c|c|c|}
\hline Variable & Lymphedema group $(\mathrm{n}=57)$ & $\begin{array}{l}\text { Non-lymphedema group } \\
\qquad(\mathrm{n}=181)\end{array}$ & $P$ value \\
\hline Age (years) ${ }^{a}$ & $55.3 \pm 10.9(53)$ & $56.4 \pm 12.8(58)$ & 0.568 \\
\hline Body mass index $\left(\mathrm{kg} / \mathrm{m}^{2}\right)^{\mathrm{a}}$ & $23.6 \pm 4.3(23)$ & $22.9 \pm 3.8(22.4)$ & 0.295 \\
\hline Follow-up period (months) ${ }^{a}$ & $32.3 \pm 11.5$ & $30.9 \pm 10.6$ & 0.308 \\
\hline Drain removal time (days) ${ }^{a}$ & $5.2 \pm 1.7(5)$ & $4.8 \pm 1.5(5)$ & 0.126 \\
\hline Level of lymph node dissection (level $1 / 2 / 3)^{b}$ & $40 / 12 / 5$ & $144 / 23 / 14$ & 0.167 \\
\hline $\begin{array}{l}\text { Presence or absence of co-resident household } \\
\text { members (yes/no) }{ }^{b}\end{array}$ & $51 / 6$ & $158 / 23$ & 0.818 \\
\hline $\begin{array}{l}\text { Radiation therapy (subclavian lymph node and } \\
\text { the anterior chest/anterior chest/no) }{ }^{b}\end{array}$ & $7 / 15 / 35$ & $25 / 36 / 120$ & 0.303 \\
\hline Neoadjuvant chemotherapy (yes/no) ${ }^{b}$ & $22 / 35$ & $47 / 134$ & 0.093 \\
\hline \multicolumn{4}{|l|}{ Adjuvant chemotherapy (n) ${ }^{b}$} \\
\hline Docetaxel and cyclophosphamide & 17 & 25 & 0.009 \\
\hline $\begin{array}{l}\text { Docetaxel and cyclophosphamide }+ \text { trastu- } \\
\text { zumab }\end{array}$ & 1 & 9 & 0.459 \\
\hline $\begin{array}{l}\text { Doxorubicin and cyclophosphamide }+ \text { pacli- } \\
\text { taxel }\end{array}$ & 1 & 13 & 0.197 \\
\hline Trastuzumab and paclitaxel & 1 & 0 & 0.239 \\
\hline Paclitaxel & 1 & 1 & 0.422 \\
\hline Other & 9 & 34 & 0.696 \\
\hline
\end{tabular}

${ }^{\mathrm{a}}$ Mean \pm standard deviation (median). 'Proportion.

Table 2. Results of logistic regression analysis

\begin{tabular}{lcc}
\hline Variable & Odds ratio (95\% CI) & P value \\
\hline Drain removal time & $1.119(0.933-1.341)$ & 0.227 \\
Level of lymph node dissection & $1.386(0.819-2.345)$ & 0.225 \\
Neoadjuvant chemotherapy & $2.310(1.067-5.000)$ & 0.034 \\
Adjuvant docetaxel and cyclophosphamide & $4.020(1.776-9.098)$ & 0.001 \\
Adjuvant doxorubicin and cyclophosphamide + paclitaxel & $0.358(0.042-3.029)$ & 0.346 \\
\hline
\end{tabular}

CI: confidence interval.

the non-lymphedema group $(\mathrm{P}<0.2)$.

The results of the logistic regression analysis are shown in Table 2. Neoadjuvant chemotherapy and adjuvant chemotherapy using TC resulted in an increased risk of developing lymphedema $(\mathrm{P}<0.05)$. The drain removal time, the level of lymph node dissection, and adjuvant chemotherapy using $\mathrm{AC}+$ paclitaxel did not affect lymphedema development.

\section{DISCUSSION}

In this study, 57 women (23.9\%) had developed lymphedema by the end of the follow-up period. The predictors of breast cancer-related lymphedema were neoadjuvant chemotherapy and adjuvant chemotherapy using TC.
Upper-limb lymphedema is a chronic disabling sequel caused by lymphatic insufficiency; its prevalence varies from $6 \%$ to $49 \%$ among patients who have undergone lymphadenectomies. ${ }^{17-19)}$ Lymphedema may present immediately or years after treatment, although the majority of cases occur during the first 18 months. ${ }^{20,21)}$ In the current study, lymphedema occurred on average 10.5 months after surgery.

Neoadjuvant therapy reduced the size of the primary tumor, eventually allowing radical or more conservative surgical interventions. In the current study, neoadjuvant chemotherapy was a risk factor for lymphedema. Neoadjuvant chemotherapy is intended for patients with lymph node metastasis or large tumor diameters, and the associated wide- ranging surgical lymph node dissection may be 
related to the occurrence of lymphedema. However, in the current study, the degree of lymph node dissection had little effect on the occurrence of lymphedema. For patients who underwent neoadjuvant chemotherapy, it was considered that fluid retention from chemotherapy may have overwhelmed the compromised lymphatic vessels after surgery.

Taxane-based chemotherapy is routinely used in the treatment of high-risk breast cancer. A side effect of taxane-based chemotherapy is skin hardening ${ }^{22,23)}$. Jung et al. reported that taxane-based chemotherapy was an independent risk factor for lymphedema on multivariate analysis in patients following axillary lymph node dissection. ${ }^{24)}$ A review comparing adjuvant chemotherapy with and without docetaxel in breast cancer patients showed that patients receiving docetaxel consistently had increased rates of edema compared with patients receiving docetaxel-free chemotherapy. ${ }^{25)}$ A common side effect of taxane-based chemotherapy, specifically docetaxel, is increased extracellular fluid, which often presents as fluid retention in the extremities. ${ }^{26-29)}$ Furthermore, docetaxel exhibits relatively greater hematologic toxicity and is more commonly associated with edema than paclitaxel is. ${ }^{30)}$ In the current study, adjuvant chemotherapy using TC was one of the risk factors for lymphedema. TC includes docetaxel, and docetaxel may have influenced the development of lymphedema. Among our findings, adjuvant chemotherapy using TC + trastuzumab had little effect on the occurrence of lymphedema. However, the number of patients in the TC + trastuzumab group may have been too small to show a significant difference.

Ridner et al. ${ }^{31)}$ found that breast cancer survivors whose BMI was $\geq 30$ at the time of breast cancer treatment were approximately 3.6 times more likely to develop lymphedema than those with a BMI $<30$. Obesity is associated with fat necrosis, poor wound healing, and infection, all of which can lead to lymphedema. People with a larger BMI need a greater volume of blood circulation and an effective lymphatic system to facilitate fluid flow, maintain circulatory balance, and prevent any imbalance in lymphatic fluid. In contrast to previous studies, we found no association between the development of lymphedema and BMI. However, it should be taken into consideration that our patients had a lower median baseline BMI than those of Ridner et al. ${ }^{31)}$ (22.4 vs. $28.8 \mathrm{~kg}$ / $\mathrm{m}^{2}$ ).

Many studies have suggested that radiotherapy is an independent risk factor of lymphedema. ${ }^{32-36)}$ Radiotherapy can cause venous occlusion within the radiation field, lymphatic damage, and oppress venous and lymphatic circulation as a result of local muscle fibrosis. ${ }^{37)}$ In contrast to the findings of previous studies, we found no association between lymphedema and radiation treatment. These differences may have resulted from the more refined radiation techniques being implemented in recent years. Moreover, lymphedema may not have occurred because the irradiation area of patients was limited to the subclavian lymph node and the anterior chest.

\section{Study Limitations}

The current study has some limitations. First, although the risk factors for lymphedema were clarified, currently, there is no known method for preventing lymphedema. Second, we did not examine whether lymphedema affects the activities of daily living and QOL. Third, from 3 months after surgery and during the follow-up period, confirmation of lymphedema depended on patients presenting with symptoms, and this may have affected the results. Further research is needed to examine these issues.

\section{CONCLUSION}

Our study showed that lymphedema occurred in $23.9 \%$ of patients after axillary lymph node dissection for breast cancer. The average time between surgery and the diagnosis of lymphedema was 10.5 months.

Neoadjuvant chemotherapy and adjuvant chemotherapy using TC presented an increased risk of developing lymphedema. Identification of these factors could help us to plan the prevention and control of lymphedema in patients after axillary lymph node dissection for breast cancer.

\section{ACKNOWLEDGMENTS}

The authors would like to thank all the patients who participated for their cooperation. This work was supported in part by AMED Practical Research for Innovative Cancer Control, Grant Number 16ck0106215.

\section{CONFLICT OF INTEREST}

The authors declare that they have no conflict of interests. 


\section{REFERENCES}

1. Hayes S, Cornish B, Newman B: Comparison of methods to diagnose lymphoedema among breast cancer survivors: 6-month follow-up. Breast Cancer Res Treat 2005;89:221-226. DOI:10.1007/s10549-004-2045-x, PMID:15754119

2. Brennan MJ, DePompolo RW, Garden FH: Focused review: postmastectomy lymphedema. Arch Phys Med Rehabil 1996;77(Suppl):S74-S80. DOI:10.1016/S00039993(96)90248-8, PMID:8599548

3. Hayes S, Janda M, Cornish B, Battistutta D, Newman B: Lymphedema secondary to breast cancer: how choice of measure influences diagnosis, prevalence, and identifiable risk factors. Lymphology 2008;41:1828. PMID:18581955

4. Ridner SH: Quality of life and a symptom cluster associated with breast cancer treatment-related lymphedema. Support Care Cancer 2005;13:904-911. DOI:10.1007/s00520-005-0810-y, PMID:15812652

5. Voogd AC, Ververs JM, Vingerhoets AJ, Roumen RM, Coebergh JW, Crommelin MA: Lymphoedema and reduced shoulder function as indicators of quality of life after axillary lymph node dissection for invasive breast cancer. Br J Surg 2003;90:76-81. DOI:10.1002/ bjs.4010, PMID:12520579

6. Mozes M, Papa MZ, Karasik A, Reshef A, Adar R: The role of infection in post-mastectomy lymphedema. Surg Annu 1982;14:73-83. PMID:7179061

7. Pyszel A, Malyszczak K, Pyszel K, Andrzejak R, Szuba A: Disability, psychological distress and quality of life in breast cancer survivors with arm lymphedema. Lymphology 2006;39:185-192. PMID:17319631

8. McWayne J, Heiney SP: Psychologic and social sequelae of secondary lymphedema. Cancer 2005;104:457-466. DOI:10.1002/cncr.21195, PMID:15968692

9. Niwinska A, Tchorzewska H, Procner M, Kraszewska E: The frequency and risk factors of developing lymphedema of the upper extremity after breast conserving therapy. Nowotwory 2005;55:213-218.

10. Park JH, Lee WH, Chung HS: Incidence and risk factors of breast cancer lymphoedema. J Clin Nurs 2008;17:1450-1459. DOI:10.1111/j.13652702.2007.02187.x, PMID:18482142
11. Thomas-MacLean RL, Hack T, Kwan W, Towers A, Miedema B, Tilley A: Arm morbidity and disability after breast cancer: new directions for care. Oncol Nurs Forum 2008;35:65-71. DOI:10.1188/08.ONF.65-71, PMID:18192154

12. Clark B, Sitzia J, Harlow W: Incidence and risk of arm oedema following treatment for breast cancer: a three-year follow-up study. QJM 2005;98:343-348. DOI:10.1093/qjmed/hci053, PMID:15820971

13. Paskett ED, Naughton MJ, McCoy TP, Case LD, Abbott JM: The epidemiology of arm and hand swelling in premenopausal breast cancer survivors. Cancer Epidemiol Biomarkers Prev 2007;16:775-782. DOI:10.1158/10559965.EPI-06-0168, PMID:17416770

14. Ridner SH, Dietrich MS: Self-reported comorbid conditions and medication usage in breast cancer survivors with and without lymphedema. Oncol Nurs Forum 2008;35:57-63. DOI:10.1188/08.ONF.57-63, PMID:18192153

15. Soran A, D’Angelo G, Begovic M, Ardic F, Harlak A, Samuel Wieand H, Vogel VG, Johnson RR: Breast cancer-related lymphedema - what are the significant predictors and how they affect the severity of lymphedema? Breast J 2006;12:536-543. DOI:10.1111/j.15244741.2006.00342.x, PMID:17238983

16. Bani HA, Fasching PA, Lux MM, Rauh C, Willner M, Eder I, Loehberg C, Schrauder M, Beckmann MW, Bani MR: Lymphedema in breast cancer survivors: assessment and information provision in a specialized breast unit. Patient Educ Couns 2007;66:311-318. DOI:10.1016/j.pec.2007.01.004, PMID:17331692

17. DiSipio T, Rye S, Newman B, Hayes S: Incidence of unilateral arm lymphoedema after breast cancer: a systematic review and meta-analysis. Lancet Oncol 2013;14:500-515. DOI:10.1016/S1470-2045(13)70076-7, PMID:23540561

18. Siegel R, DeSantis C, Virgo K, Stein K, Mariotto A, Smith T, Cooper D, Gansler T, Lerro C, Fedewa S, Lin C, Leach C, Cannady RS, Cho H, Scoppa S, Hachey M, Kirch R, Jemal A, Ward E: Cancer treatment and survivorship statistics, 2012. CA Cancer J Clin 2012;62:220 241. DOI:10.3322/caac.21149, PMID:22700443

19. Tsai RJ, Dennis LK, Lynch CF, Snetselaar LG, Zamba GK, Scott-Conner C: The risk of developing arm lymphedema among breast cancer survivors: a meta-analysis of treatment factors. Ann Surg Oncol 2009;16:1959-1972. DOI:10.1245/s10434-009-0452-2, PMID:19365624 
20. Petrek JA, Senie RT, Peters M, Rosen PP: Lymphedema in a cohort of breast carcinoma survivors 20 years after diagnosis. Cancer 2001;92:1368-1377. DOI:10.1002/1097-0142(20010915)92:6<1368::AIDCNCR1459>3.0.CO;2-9, PMID:11745212

21. Edwards TL: Prevalence and aetiology of lymphoedema after breast cancer treatment in southern Tasmania. ANZ J Surg 2000;70:412-418. DOI:10.1046/j.14401622.2000.01839.x, PMID:10843395

22. Takahashi T, Asano Y, Ichimura Y, Taniguchi T, Kogure A, Tamaki Z, Takekoshi T, Sugaya M, Sato S: A case of taxane-induced scleroderma: a different expression profile of Fli1 proteins in dermal fibroblasts and microvascular endothelial cells compared with systemic sclerosis. Br J Dermatol 2011;164:1393-1395. DOI:10.1111/ j.1365-2133.2011.10243.x, PMID:21299546

23. Battafarano DF, Zimmerman GC, Older SA, Keeling JH, Burn's HA: Docetaxel (Taxotere) associated scleroderma-like changes of the lower extremities. A report of three cases. Cancer 1995;76:110-115.DOI:10.1002/10970142(19950701)76:1<110::AID-CNCR2820760117>3.0.CO;2-9, PMID:8630861

24. Hugenholtz-Wamsteker W, Robbeson C, Nijs J, Hoelen W, Meeus M: The effect of docetaxel on developing oedema in patients with breast cancer: a systematic review. Eur J Cancer Care (Engl) 2016;25:269-279. DOI:10.1111/ecc.12261, PMID:25348689

25. Jung SY, Shin KH, Kim M, Chung SH, Lee S, Kang HS, Lee ES, Kwon Y, Lee KS, Park IH, Ro J: Treatment factors affecting breast cancer-related lymphedema after systemic chemotherapy and radiotherapy in stage II/III breast cancer patients. Breast Cancer Res Treat 2014;148:91-98. DOI:10.1007/s10549-014-3137-X, PMID:25253173

26. Goble S, Bear HD: Emerging role of taxanes in adjuvant and neoadjuvant therapy for breast cancer. Surg Clin North Am 2003;83:943-971. DOI:10.1016/S00396109(03)00071-9, PMID:12875604

27. Ohsumi S, Shimozuma K, Ohashi Y, Takeuchi A, Suemasu K, Kuranami M, Ohno S, Watanabe T: Subjective and objective assessment of edema during adjuvant chemotherapy for breast cancer using taxane-containing regimens in a randomized controlled trial: The National Surgical Adjuvant Study of Breast Cancer 02. Oncology 2012;82:131-138. DOI:10.1159/000336480, PMID:22433221
28. Qin YY, Li H, Guo XJ, Ye XF, Wei X, Zhou YH, Zhang XJ, Wang C, Qian W, Lu J, He J: Adjuvant chemotherapy, with or without taxanes, in early or operable breast cancer: a meta-analysis of 19 randomized trials with 30698 patients. PLoS One 2011;6:e26946. DOI:10.1371/ journal.pone.0026946, PMID:22069477

29. Brønstad A, Berg A, Reed RK: Effects of the taxanes paclitaxel and docetaxel on edema formation and interstitial fluid pressure. Am J Physiol Heart Circ Physiol 2004;287:H963-H968. DOI:10.1152/ajpheart.01052.2003, PMID:15059777

30. Sparano JA, Wang M, Martino S, Jones V, Perez EA, Saphner T, Wolff AC, Sledge GW Jr, Wood WC, Davidson NE: Weekly paclitaxel in the adjuvant treatment of breast cancer. N Engl J Med 2008;358:1663-1671. DOI:10.1056/NEJMoa0707056, PMID:18420499

31. Ridner SH, Dietrich MS, Stewart BR, Armer JM: Body mass index and breast cancer treatment-related lymphedema. Support Care Cancer 2011;19:853-857. DOI:10.1007/s00520-011-1089-9, PMID:21240649

32. Herd-Smith A, Russo A, Muraca MG, Del Turco MR, Cardona G: Prognostic factors for lymphedema after primary treatmentofbreastcarcinoma.Cancer2001;92:1783-1787. DOI:10.1002/1097-0142(20011001)92:7<1783::AIDCNCR1694>3.0.CO;2-G, PMID:11745250

33. Engel J, Kerr J, Schlesinger-Raab A, Sauer H, Hölzel D: Axilla surgery severely affects quality of life: results of a 5-year prospective study in breast cancer patients. Breast Cancer Res Treat 2003;79:47-57. DOI:10.1023/A:1023330206021, PMID:12779081

34. Geller BM, Vacek PM, O'Brien P, Secker-Walker RH: Factors associated with arm swelling after breast cancer surgery. J Womens Health (Larchmt) 2003;12:921-930. DOI:10.1089/154099903770948159, PMID:14670172

35. Deo SV, Ray S, Rath GK, Shukla NK, Kar M, Asthana S, Raina V: Prevalence and risk factors for development of lymphedema following breast cancer treatment. Indian J Cancer 2004;41:8-12. PMID:15105573

36. Lee SH, Min YS, Park HY, Jung TD: Health-related quality of life in breast cancer patients with lymphedema who survived more than one year after surgery. J Breast Cancer 2012;15:449-453. DOI:10.4048/ jbc.2012.15.4.449, PMID:23346175

37. Zhu YQ, Xie YH, Liu FH, Guo Q, Shen PP, Tian Y: Systemic analysis on risk factors for breast cancer related lymphedema. Asian Pac J Cancer Prev 2014;15:6535-6541. DOI:10.7314/APJCP.2014.15.16.6535, PMID:25169483 